\title{
Laparoscopic Radical Prostatectomy: 10 Years Experience
}

\author{
Mirandolino B. Mariano, Marcos V. Tefilli, Gilvan N. Fonseca, Isidoro H. Goldraich
}

Section of Urology (MBM), Santa Casa de Misericordia de Porto Alegre, Section of Urology (MBM, $I H G)$, Hospital Moinhos de Vento, Porto Alegre, Section of Urology (MVT), Hospital Mae de Deus, Porto Alegre, Rio Grande do Sul, and Section of Urology (GNF), University Hospital, School of Medicine, Federal University of Goias, Goias, Brazil

\begin{abstract}
Purpose: The authors assess the morbidity, functional results and oncologic follow-up of a series of laparoscopic radical prostatectomies performed in over a 10-year period.

Materials and Methods: The data on 780 laparoscopic radical prostatectomies performed between September 1997 and December 2007 were stored in a personal database. The following parameters are described and critically analyzed: operative time, blood transfusions, conversions, length of hospital stay, complications, functional results of sexual potency and urinary continence, surgical margins and oncologic follow-up.

Results: Operative time averaged 125 minutes, with a mean bleeding volume of $335 \mathrm{~mL}$ and mean hospital stay of 4.3 days. The rate of conversion to open surgery was $1.36 \%$ and the overall complication rate was $14.24 \%$. The pathology analysis showed pT2 tumors in $82.60 \%$ and pT3 tumors in $17.39 \%$ of cases. The overall positive margin rate was $19.58 \%$, with a biochemical recurrence of $10.27 \%$ at a mean follow-up of 62.5 months. Urinary continence and sexual potency yielded rates of $88 \%$ and $61 \%$, respectively, 12 months after surgery.

Conclusions: Laparoscopic radical prostatectomy is a technically well-defined procedure that provides good oncologic and functional results after proper training.
\end{abstract}

Key words: prostatic neoplams; prostatectomy; laparoscopic surgery; outcomes

Int Braz J Urol. 2009; 35: 565-72

\section{INTRODUCTION}

Even though there is no consensus on the best therapeutic approach to prostate cancer, radical prostatectomy is regarded as the treatment of choice by most urologists. Radical retropubic prostatectomy has been the gold standard worldwide, allowing for high rates of cancer control with low rates of incontinence and sexual dysfunction. Laparoscopy has been used as an alternative procedure, combining the principles of anatomic radical prostatectomy with the advantages of minimally invasive surgery (1-6). In this report, the authors describe technical aspects and complica- tions, as well as oncologic and functional results of laparoscopic radical prostatectomy (LRP) within a 10 -year period.

\section{MATERIALS AND METHODS}

A total of 780 patients with clinically localized prostate cancer were submitted to LRP by one of the authors, between September 1997 and December 2007. The patients were recruited from the authors' private practices or were referred for surgery by other physicians. The data were stored and updated accord- 
ing to outpatient follow-up retrospectively in a data base. Fifty patients were excluded from the analysis due to loss to follow-up and/or inadequate records.

The transperitoneal approach was used in 559 cases and the preperitoneal approach was used in 171 cases. Technically, we removed all of the preprostatic fat and approached the endopelvic fascia with clear exposure of puboprostatic ligaments and their lateral limits. Puboprostatic ligaments were not sectioned and, additionally, we used a metal urethral sound for precise identification of the urethra and its posterior mobilization, thus allowing for the safe passage of two figure of eight 2-0 vycril sutures. The ligation of arterial lateral prostatic pedicles can be safely obtained with the harmonic scalpel, bipolar cautery, using clips or intracorporeal suture at the surgeon's discretion, in order to avoid any form of energy close to the pedicles. We also have used only cold scissors close to the seminal vesicles and posterolateral neurovascular bundle, using only intracorporeal suture or polymer clips for hemostasis.

Postoperative assessments included clinical examination and the prostate-specific antigen (PSA) test, which was performed every three months in the first two years, every six months from the third to the fifth years, and once a year thereafter. Radiological examination was requested, if clinically indicated. Biochemical recurrence was defined as two PSA measurements above $0.2 \mathrm{ng} / \mathrm{mL}$.

Pathology data were obtained from pathology reports and, if necessary, the slides were reviewed.
The 1997 TNM classification system was used for staging and the Gleason score was employed for tumor grade (7). A positive surgical margin after radical prostatectomy was defined as the spread of the tumor to the inked margin of the surgical specimen on microscopic examination. Pelvic lymphadenectomy was indicated for patients with Gleason score greater than 7 and/or PSA greater than $10 \mathrm{ng} / \mathrm{dL}$, which was required in 76 cases $(10.41 \%)$. In the present series, patients with positive lymph nodes were excluded from radical surgery for cancer.

Data on sexual potency and urinary continence were obtained from outpatient records. Urinary incontinence was regarded as the use of any protection against urinary leakage, and erectile dysfunction was defined as spontaneous and permanent inability to achieve sufficient erection for vaginal penetration.

\section{RESULTS}

A total of 730 patients with mean age of 64.6 years (42 to 76, SD 4.09) and clinically localized disease were selected for this review. The PSA ranged from 2.80 to $16 \mathrm{ng} / \mathrm{mL}$, (mean of $6.15 \mathrm{ng} / \mathrm{mL}$, SD 1.14). Data regarding demographics are summarized in Table-1.

Operative time averaged 124.97 minutes (90 to 240, SD 20.11), with a mean hospital stay of 4.30 days (1.5 to 20, SD 2.14 ). When pelvic lymphadenectomy was performed, operative time increased by 40

Table 1 - Patients demographics in the present series.

\begin{tabular}{lrrrr}
\hline Variable & Mean & SD & Minimum & Maximum \\
\hline Age & 64.60 & 4.09 & 42.00 & 76.00 \\
Weight & 77.46 & 7.28 & 60.00 & 123.00 \\
Height & 1.74 & 0.06 & 1.60 & 2.05 \\
BMI & 25.62 & 1.99 & 20.90 & 38.80 \\
PSA pre & 6.15 & 1.14 & 2.80 & 16.00 \\
Operative time & 124.97 & 20.11 & 90.00 & 240.00 \\
Blood loss & 335.92 & 79.99 & 50.00 & 1150.00 \\
Hospital stay & 4.30 & 2.14 & 0.00 & 20.00 \\
Catheter time & 8.00 & 1.31 & 0.00 & 18.00 \\
\hline
\end{tabular}

$B M I=$ body mass index, $P S A=$ prostatic specific antigen. 
minutes. The mean time of urinary catheterization was eight days (7 a 18, SD 1.31).

The mean bleeding volume during the intraoperative period was $335 \mathrm{~mL}(50-1.150 \mathrm{~mL}$, SD 79.99), with transfusion rates of 5.34\% (39 cases). None of these patients required reoperation.

The rate of conversion to the open technique was $1.36 \%$ (10 cases), with an overall complication rate of $14.24 \%$ (104 cases). The data are summarized in Table- 2 .

The pathological assessment revealed $\mathrm{pT} 2 \mathrm{a} / \mathrm{b}$ tumors in $19.45 \%$ of cases (142 patients), pT2c tumors in $63.15 \%$ of cases (461 patients), pT3a/b tumors in $14.38 \%$ of cases (105 patients) and pT3c tumors in $3.10 \%$ of cases (22 patients). The Gleason score was distributed as follows: 2 to 4 in 3.97\% (29 cases), 5 to 6 in $44.93 \%$ (328 cases), 7 in $46.02 \%$ (336 cases) 8 to 10 in $5.06 \%$ ( 37 cases). The mean overall positive margin rate was $19.58 \%$ (143 cases): $7.69 \%$ for $\mathrm{pT} 2 \mathrm{a} /$ b (11 cases), $19.08 \%$ for pT2c (88 cases), $34.28 \%$ for $\mathrm{pT} 3 \mathrm{a} / \mathrm{b}$ (36 cases) and $36.36 \%$ for pT3c ( 8 cases). The positive surgical margins were located as follows: in the apical region $49.65 \%$ (71 patients), at the bladder neck $20.27 \%$ (29 patients) and in the posterolateral

Table 2 - Complication rates and results for laparoscopic radical prostatectomy.

\begin{tabular}{lc}
\hline Complications (total) & $\mathbf{1 4 . 2 4 \%}(\mathrm{N}=104)$ \\
\hline Major complications & \\
$\quad$ Mortality & $0.13 \%(\mathrm{~N}=1)$ \\
Reoperations & $0.27 \%(\mathrm{~N}=2)$ \\
Conversion & $1.36 \%(\mathrm{~N}=10)$ \\
Rectal injury & $0.54 \%(\mathrm{~N}=4)$ \\
Ileocolonic injury & $0.13 \%(\mathrm{~N}=1)$ \\
Ureteral injury & $0.54 \%(\mathrm{~N}=4)$ \\
Minor complications & \\
Deep vein thrombosis & $0.68 \%(\mathrm{~N}=5)$ \\
$\quad$ Urinary leakage & $6.98 \%(\mathrm{~N}=51)$ \\
$\quad$ Urethrovesical stenosis & $2.46 \%(\mathrm{~N}=18)$ \\
$\quad$ Urinary retention & $1.09 \%(\mathrm{~N}=8)$ \\
*Urinary incontinence & $12.1 \%(\mathrm{~N}=88)$ \\
*Erectile dysfunction & $39.1 \%(\mathrm{~N}=285)$ \\
\hline
\end{tabular}

*Not included in the overall analysis of complications.
Table 3 - Oncologic results of the present series.

\begin{tabular}{lrr}
\hline Criterion & \% & N \\
\hline Clinical stage & & \\
T1a/b & 3 & 22 \\
T1c & 18 & 131 \\
T2 & 79 & 577 \\
Pathological stage & & \\
pT2a/b & 19.45 & 142 \\
pT2c & 63.15 & 461 \\
pT3a/b & 14.38 & 105 \\
pT3c & 3.01 & 22 \\
Positive margin rate & & \\
Overall & 19.58 & 143 \\
$\quad$ pT2a/b & 7.74 & 11 \\
$\quad$ pT2c & 19.08 & 88 \\
pT3a/b & 34.28 & 36 \\
pT3c & 36.36 & 8 \\
Location of the margins & & \\
Apical & 49.65 & 71 \\
Bladder neck & 20.27 & 29 \\
Posterolateral & 30.06 & 43 \\
Biochemical recurrence rate & & \\
Overall & 10.27 & 75 \\
\hline
\end{tabular}

region $30.06 \%$ (43 patients). Table- 3 summarizes the data on surgical margins.

In this series with a minimum follow-up of 5 months and maximum follow-up of 120 months (mean of 62.5 months), the overall rate of biochemical recurrence was $10.3 \%$ (75 patients). The mean time for neoplasm recurrence was 9 months.

Urinary continence had a rate of $87.94 \%(642$ patients) 12 months after surgery. Sexual potency yielded a rate of $60.95 \%$ (445 patients) in the same period. In this group of patients who remained potent postoperatively, bilateral preservation of the neurovascular bundle was performed in $77 \%$ of the cases (343 patients), unilateral preservation in $19.5 \%$ of the cases (87 patients), and the neurovascular bundles were not preserved in $3.3 \%$ of the cases (15 patients) (Table-4). 
Table 4 - Data regarding erectile function and neurovascular bundle preservation.

\begin{tabular}{cc}
\hline Total & 730 Cases \\
\hline No nerve sparing & $58(8 \%)$ \\
Unilateral nerve sparing & $168(23 \%)$ \\
Bilateral nerve sparing & $504(69 \%)$ \\
Potent & $445(60.9 \%)$ \\
No nerve sparing & $15(3.37 \%)$ \\
Unilateral nerve sparing & $87(19.5 \%)$ \\
Bilateral nerve sparing & $343(77 \%)$ \\
\hline
\end{tabular}

\section{COMMENTS}

The mean intraoperative bleeding volume in the present series amounted to $300 \mathrm{~mL}$ with transfusion rates up to $5 \%$. Major bleeding in radical prostatectomy, both in the open and laparoscopic techniques, occurs while controlling the dorsal venous complex and while ligating the lateral prostatic pedicles. Laparoscopy offers increased magnification, excellent illumination and a tamponade effect of $\mathrm{CO}_{2}$, which facilitates hemostasis and visualization. Safe ligation of the dorsal vein complex is performed under good anterior and lateral visualization of the venous plexus and of its lower limit, close to the urethra (1-6,8-12).

Different types of complications have been reported in up to $35 \%$ of the cases, but most of them have negligible clinical consequences (1-18). Mortality has reported to be approximately from 0.5 to $1 \%$, and has been related to heart diseases or cases of pulmonary embolism. All reported series on LRP show a tendency towards the reduction of postoperative complication rates, from $25 \%$ to approximately $5 \%$ after the learning curve has been achieved $(3,5,6,10,12-17)$.

Rectal injuries are potential complications of radical prostatectomy, with rates between 0 and $9 \%$ being described in LRP series $(15,18)$. These injuries often occur at the end of the excision of the prostate gland, or during the dissection of the lateral pedicles or while sectioning the rectourethralis muscle adja- cent to the prostatic apex. When these injuries occur during the intraoperative period, they must be corrected by laparoscopy with a primary suture, and the suture must be "strengthened" with omentum or preperitoneal fat. Most cases have a favorable outcome with the primary suture and occasionally with protective colostomy, if necessary, depending on the extent of the injury and level of local contamination. The conservative management with derivative colostomy for up to three months has been the initial approach in these cases, provided that no sepsis is associated. However, spontaneous closure is extremely rare and most patients require surgical treatment. Abdominal (either open or laparoscopic), perineal or posterior transphincteric approaches have been used to correct these rectourethral fistulas, although no agreement exists on the best therapeutic approach that should be used. The closure of rectourinary fistulas in our setting have been performed laparoscopically by the abdominal approach, even though we recognize that the sagittal transphincteric approach is a good alternative. In our patient population, we had four rectal injuries, two of which were identified and sutured in the intraoperative period, resolving uneventfully. One of the injuries was detected when the catheter was removed, and was treated with derivative colostomy and corrected laparoscopically three months afterwards. The other injury consisted of low output fistula, which closed spontaneously with an indwelling catheter.

Ureteral injuries yield rates of $0.5 \%$ in LRP, and occurs mainly in three situations: 1) when we mistake the vas deferens for the ureter; 2) when a previous transurethral resection was made, which prevents the proper visualization of ureteral meatus at the bladder neck; 3 ) when the ureter is enveloped by a urethrovesical anastomosis $(2,5,10,12,15)$. Treatment usually consists of laparoscopic ureteral reimplantation. In our patient population, we had three cases of ureteral injuries, one during the intraoperative period, corrected with laparoscopic reimplantation, and two cases in which the ureter was enveloped by the anastomosis, where correction consisted of ureteral reimplantation in a reoperation.

Urethrovesical anastomosis is the most technically challenging step of the procedure. Although laparoscopy provides ideal illumination and increased magnification for the sutures, their accurate place- 
ment depends on expertise in intracorporeal suturing, which needs to be standardized. Separate stitches or continuous suture can be used, but we have preferred the latter, since it reduces the number of knots, which subsequently facilitates the procedure. With regard to complications related to laparoscopic urethrovesical anastomosis, anastomotic leak occurs in approximately $10 \%$ of cases, but it usually resolves spontaneously with bladder drainage and maintaining a suprapubic drain. In our patient population, all cases resolved spontaneously with bladder drainage and maintenance of the drain. One case required drainage for up to three weeks, with maintenance of the bladder catheter and of the suprapubic drain throughout the period.

The conversion rate is on average $2.4 \%$ ( 0 to $14 \%$ ), and is predominantly required due to technical reasons, such as bleeding, adhesions or excessive operative time, without severe complications (15). In our experience, after the first 10 cases requiring conversion, there were no other conversions to open surgery.

Urinary continence rates after open radical prostatectomy have ranged from $31 \%$ to $92 \%$. In most laparoscopic series, the rates of urinary control at 3,6 and 12 months have been around $58 \%, 68 \%$ and 82 to $91 \%$, respectively $(5,14,15)$. It should be kept in mind that urinary continence rates are higher and better in younger individuals and where the neurovascular bundles were preserved. Some authors have shown that patients achieve urinary control earlier after LRP compared to open retropubic surgery $(6,8)$. Using the experience gained in LRP, some maneuvers have been developed in order to improve urinary control rates. The so-called "urethral stretching" can be performed and consists of dissection of the urethra, proximal to the urinary sphincteric region, which permits suturing with less tensile strength without enveloping the pelvic musculature and consequently the striated sphincter. In addition, the preservation of the bladder neck in patients with low risk for cancer may be of some benefit.

Rates of sexual function preservation range considerably from $11 \%$ to $85 \%$ in the reported series of retropubic radical prostatectomies. Our criteria for the preservation of the neurovascular bundle are based on the parameters of age, clinical staging, transoperative impression and preoperative function parameters. Again, sexual function recovery depends on age and on the preservation of neurovascular bundles. There was a gradual temporal recovery, according to follow-up assessments at 3, 6, 12 and 18 months with rates of $38 \%, 54 \%, 73 \%$ and $86 \%$ in the best series. In reported laparoscopic series, the mean erectile function rate was $59 \%$ at 6 months $(3,5,12,13,15)$. Technically, laparoscopy can provide as good results as those of the open surgery in terms of preservation of sexual potency. In addition to excellent anatomic expertise, contributing factors include increased magnification, excellent illumination and reduced local bleeding. The control of lateral prostatic pedicles and vessels at the apex of the seminal vesicles with clips or manual suture, using cold scissors, has been invaluable, avoiding the use of thermal energy close to the neurovascular bundle.

Positive margin rates vary widely in the literature, from $5 \%$ to $45 \%$, depending on the tumor stage, tumor differentiation, technique used and surgeon's expertise. Positive surgical margins in retropubic radical prostatectomies yield rates of $16 \%$ to $28 \%$ for pT2 tumors, and up to $47 \%$ to $52 \%$ for pT3 tumors. If we consider patients with nonpalpable tumors diagnosed through abnormal PSA levels, positive margin rates can be as low as $8 \%(2,6,9,12,15)$.

In several LRP series, positive margin rates have been quite similar to those described for retropubic prostatectomies, depending basically on the extent of the disease. The mean positive margin rates for $\mathrm{pT} 1 / \mathrm{pT} 2$ tumors have ranged between $11 \%$ and $26 \%$, amounting on average to $4 \%$ for $\mathrm{pT} 1 / \mathrm{pT} 2 \mathrm{a} / \mathrm{b}$ and to $18 \%$ for pT2c. For advanced-stage tumors, the rates increase from $33 \%$ to $39 \%$ for pT3a and to $81 \%$ for pT3b. Positive surgical margins in LRP in most series are located in the apical region (50 to 70\%), basal region $(10 \%)$, posterolateral region (10 to $25 \%$ ), anterior region $(5 \%)$ and multiple regions $(5 \%)(2,6,9,12,15)$. In our patient population, we had an overall positive margin rate of $19.58 \%: 7.69 \%$ for $\mathrm{pT} 2 \mathrm{a} / \mathrm{b}, 19.08 \%$ for pT2c, $34.5 \%$ for $\mathrm{pT} 3 \mathrm{a} / \mathrm{b}$ and $36.3 \%$ for $\mathrm{pT} 3 \mathrm{c}$. With regard to the location of surgical margins, $49.7 \%$ of the cases showed apical margins, $29.9 \%$ posterolateral margins and $20.3 \%$ bladder neck margins.

Based on our experience, apical dissection is a crucial step in LRP since it plays an important role in urinary continence (length of urethral stump, quality of the anastomosis and sphincter control), erectile dys- 
function (injury to the neurovascular bundle), surgical margins and risk of rectal injury. We have observed that urethral transection at the end of the procedure after total release of both neurovascular bundles, as well as the preservation of the bladder neck only in cases with safe clinical characteristics of localized disease could be the two most important factors for the reduction of positive margins. Ran et al. demonstrated that good apical dissection with sectioning of puboprostatic ligaments and the nonpreservation of the bladder neck decreased the positive margin rate to $0 \%$ at the bladder neck and from $12 \%$ to $6 \%$ at the apex (11). Although we have an optimal positive margin rate, our rate of posterolateral margins was high, perhaps due to considerable concern with sexual potency and its preservation, a fact that has been reconsidered in some situations.

The biochemical recurrence rates, have amounted to $11 \%$ for patients with clinically localized disease and follow-up of 5 years, outperforming the statistics of large series of retropubic radical prostatectomies $(2,6,9,11,12,15,19,20)$. If observed more closely, the rates of biochemical recurrence in LRP were $8.6 \%$ (4 to $15.3 \%$ ) for pT2 and $17.5 \%$ (15 to $20.6 \%$ ) for pT3 in periods of up to 5 years. The disease-free survival rates have reached $92 \%$ for pT2a/bN0; $88 \%$ for $\mathrm{pT} 2 \mathrm{cN} 0 ; 77 \%$ for $\mathrm{pT} 3 \mathrm{aN} 0 ; 44 \%$ for $\mathrm{pT} 3 \mathrm{bN} 0$ and $50 \%$ for $\mathrm{pT} 1-3 \mathrm{~N} 1$. Open radical prostatectomies have yielded biochemical control rates of $88 \%$ to $93 \%$ for pT $1-2 \mathrm{~N} 0,75 \%$ for $\mathrm{pT} 3 \mathrm{aN} 0$ and $47 \%$ for patients with invasion of the seminal vesicles. Our rate of biochemical control has averaged $10.3 \%$ with a mean follow-up of 62.5 months.

\section{CONCLUSIONS}

Laparoscopic radical prostatectomy is a technically well-defined procedure that provides good oncologic and functional results after proper training. It is currently our treatment of choice for prostate cancer patients.

\section{CONFLICT OF INTEREST}

None declared.

\section{REFERENCES}

1. Schuessler WW, Schulam PG, Clayman RV, Kavoussi LR: Laparoscopic radical prostatectomy: initial shortterm experience. Urology. 1997; 50: 854-7.

2. Guillonneau B, Cathelineau X, Barret E, Rozet F, Vallancien G: Laparoscopic radical prostatectomy: technical and early oncological assessment of 40 operations. Eur Urol. 1999; 36: 14-20.

3. Guillonneau B, Vallancien G: Laparoscopic radical prostatectomy: the Montsouris technique. J Urol. 2000; 163: 1643-9.

4. Rassweiler J, Sentker L, Seemann O, Hatzinger M, Rumpelt HJ: Laparoscopic radical prostatectomy with the Heilbronn technique: an analysis of the first 180 cases. J Urol. 2001; 166: 2101-8.

5. Türk I, Deger S, Winkelmann B, Schönberger B, Loening SA: Laparoscopic radical prostatectomy. Technical aspects and experience with 125 cases. Eur Urol. 2001; 40: 46-52; discussion 53.

6. Rassweiler J, Schulze M, Teber D, Seemann O, Frede $\mathrm{T}$ : Laparoscopic radical prostatectomy: functional and oncological outcomes. Curr Opin Urol. 2004; 14: 7582.

7. Flemming ID, Cooper JS, Hemson M: In: American joint committee on cancer staging manual. 5th ed. Philadelphia, JB Lippincott. 1997; pp. 219-22.

8. Curto F, Benijts J, Pansadoro A, Barmoshe S, Hoepffner JL, Mugnier C, et al.: Nerve sparing laparoscopic radical prostatectomy: our technique. Eur Urol. 2006; 49: 344-52.

9. Guillonneau B, el-Fettouh H, Baumert H, Cathelineau X, Doublet JD, Fromont G, et al.: Laparoscopic radical prostatectomy: oncological evaluation after 1,000 cases a Montsouris Institute. J Urol. 2003; 169: 12616.

10. Mariano MB, Goldraich IH, Tefilli MV: Experiência com 450 prostatectomias radicais laparoscópicas. Int Braz J Urol. 2005; 30: (Special Suppl.): 68. Abstract \# TL 303.

11. Katz R, Salomon L, Hoznek A, de la Taille A, Antiphon $\mathrm{P}$, Abbou CC: Positive surgical margins in laparoscopic radical prostatectomy: the impact of apical dissection, bladder neck remodeling and nerve preservation. J Urol. 2003; 169: 2049-52.

12. Galli S, Simonato A, Bozzola A, Gregori A, Lissiani A, Scaburri A, et al.: Oncologic outcome and continence recovery after laparoscopic radical prostatectomy: 3 years' follow-up in a "second generation center". Eur Urol. 2006; 49: 859-65. 
13. Guillonneau B, Cathelineau X, Doublet JD, Vallancien G: Laparoscopic radical prostatectomy: the lessons learned. J Endourol. 2001; 15: 441-5; discussion 4478.

14. Türk I, Deger S, Winkelmann B, Schönberger B, Loening SA: Laparoscopic radical prostatectomy. Technical aspects and experience with 125 cases. Eur Urol. 2001; 40: 46-52; discussion 53.

15. Rassweiler J, Stolzenburg J, Sulser T, Deger S, Zumbé J, Hofmockel G, et al.: Laparoscopic radical prostatectomy--the experience of the German Laparoscopic Working Group. Eur Urol. 2006; 49: 113-9.

16. Guillonneau B, Rozet F, Cathelineau X, Lay F, Barret E, Doublet JD, et al.: Perioperative complications of laparoscopic radical prostatectomy: the Montsouris 3-year experience. J Urol. 2002; 167: 51-6.
17. Vallancien G, Gupta R, Cathelineau X, Baumert H, Rozet F: Initial results of salvage laparoscopic radical prostatectomy after radiation failure. J Urol. 2003; 170: 1838-40.

18. Castillo OA, Bodden EM, Vitagliano GJ, Gomez R: Anterior transanal, transsphincteric sagittal approach for fistula repair secondary to laparoscopic radical prostatectomy: a simple and effective technique. Urology. 2006; 68: 198-201.

19. Bove P, Asimakopoulos AD, Kim FJ, Vespaiani G: Laparoscopic radical prostatectomy: A review. Int Braz J Urol. 2009; 35: 125-29.

20. Eden CG, Neill MG, Louie-Johnsun MW: The first 1000 cases of laparoscopic radical prostatectomy in the UK: evidence of multiple 'learning curves'. BJU Int. 2009; 103: 1224-30.

Accepted after revision:

June 9, 2009

\section{Correspondence address:}

Dr. Mirandolino Batista Mariano

Rua Costa, 30 / 803

Porto Alegre, RS, 90110-270, Brazil

Fax: + $55513231-7247$

E-mail: mirandolino@terra.com.br

\section{EDITORIAL COMMENT}

The authors deserve to be congratulated, not only for the large amount of cases that were presented, but mostly due to the fact that they kept the data organized for over the years, which is absolutely unusual in our medical community, especially when the cases come from a private service, outside of an academic environment, as in this case.

As every retrospective work, there are a few flaws that do not in any way diminish the authors' ef- fort. The Gleason criterion has changed over the years and the cases with Gleason 5 or less probably would not resist a revision. It is also important to notice that different pathologists examined the specimens, which could introduce an important bias to the results. The evaluation of the erectile function was not done before the operations, which complicates the interpretation of the apparently excellent rates of erectile function preservation. 
However, it is important to point out the positive aspects of the work. The average operation time of 125 minutes is better than that of most of the major serious studies that were published. The amount of blood loss, in average $335 \mathrm{~mL}$, and the conversion rate of $1.36 \%$, indicate a good and well established technique by the authors. The long period of followup, of 62.5 months, gives credibility to the results and consistency to the work.
This paper, which is the most important ever published in our medical community about radical laparoscopic prostatectomy, comes at a good moment, in which the first preliminary series of robot-assisted laparoscopic prostatectomy are being carried out. The results of future years must necessarily be compared to those of this excellent work, which I personally consider the gold-standard of radical laparoscopic prostatectomy.
Dr. Lisias N. Castilho Catholic University Campinas, SP, Brazil E-mail:lisias@dglnet.com.br 